the final responsibility must be personal. It invited each national organization to study the problem. Those who might consider this a mild achievement, or who regret the absence of any mention of the dangers of excessive childbearing on the health of the mother or her ability to bring up her family healthily, should remember that the W.M.A.'s resolution had to prove acceptable to doctors from all over the world and of all creeds.

Medical education is another of the W.M.A.'s chosen fields. The Assembly approved plans to hold a fourth World Conference, on the theme "Medical Education: A Collective Responsibility." Under this it is hoped to include the education of paramedical workers. Certainly their increasingly important place in the medical team justifies this. The conference will be held in Europe in 1972, and national medical associations are to be asked to suggest subjects and speakers and to set about raising funds for it. With Britain's entry into the Common Market on the cards, this conference could provide a useful clearing house for information about medical education in Europe, and for this reason alone should evoke the interest of the profession in Britain.
The W.M.A. is a federation of national medical associations from 59 countries, together representing some 700,000 doctors. ${ }^{4}$ Through its regional offices and its committee on medico-social affairs, which deals with the payment of doctors and social legislation affecting medical practice, it keeps member associations in touch with developments in other parts of the world. As communications shorten and the world contracts an increasing number of medical questions need debate or action on an international rather than a national or regional level. Some are most appropriately dealt with by the World Health Organization, an intergovernmental body; others by the W.M.A. What the W.M.A. is able to achieve depends on how much its members are prepared to put into it. Medicine is not one of the fields in which Britain has declined as a world force, and the British Medical Association should not be grudging in its support for the W.M.A.

\author{
1 See Brit. med. f., 1964, 2, 177 \\ 2 Ibid., 1967, 3, 429. \\ s Wld med. 7., 1967, 14, No. 5 (September-October, 1967). \\ 4 Romualdez, A. Z., Medecina de España, 1967, 3, No. 14, p. 19.
}

The specific aetiology of human leukaemia is unknown. But the leukaemias of some animals (mice and cats) can undoubtedly be transmitted by specific agents with viral characteristics. ${ }^{12}$ It is therefore tempting to seek evidence for leukaemogenic viruses or infective agents in man.

Such evidence can be obtained in two ways-firstly, by a direct search for identifiable virus particles in leukaemic cells, and secondly by an epidemiological approach aimed at detecting associations of cases of leukaemia in time and place. Though the experimental quest for specific infective agents in human leukaemia has so far been inconclusive, ${ }^{3}$ investigators in different countries have reported "clustering" -that is, the close occurrence in place and time of cases of leukaemia. Among the earliest reports are those of C. Aubertin and P. G. Bosviel ${ }^{4}$ and C. E. Kellett. ${ }^{5}$ More recently G. $\operatorname{Knox}^{6}$ has presented statistical evidence for clustering in north-east England. These and other observations $^{78}$ support the possibility that an infective agent might contribute in some way to the causation of human leukaemia. But epidemiological opinion is not unanimous, because some investigators ${ }^{9-12}$ have failed to find evidence of clustering.

The detection of significant clustering requires reliable diagnostic and statistical techniques, and in this issue of the B.M.F. we publish two more papers reporting careful analyses of cases in the London area. Dr. S. P. Lock and Mrs. Maxine Merrington (page 759) have analysed 115 cases of all types of leukaemia in both adults and children diagnosed between January 1957 and December 1963. The area covered was the former London borough of Lewisham. In the other paper Drs. Morwenna M. Till, R. M. Hardisty, M. C. Pike, and Richard Doll (page 755) report their studies of a larger series restricted to children who developed leukaemia under 10 years of age while resident in Greater London during the period 1952-61. Lock and Merrington confined their analysis to the date and place of residence of the patient at the onset of the disease, while Till and her colleagues extended their study to include information about the patients' date and place of birth. The latter workers point out that factors of aetiological importance are likely to exert their effect a considerable time before the disease becomes clinically apparent, and indeed the experimental work on the animal leukaemias has shown that the disease was most successfully transmitted when the animals were inoculated at or about the time of birth. Thus, if a virus is a cause of the disease, space-time clustering of births rather than time of onset might be more likely.

Both groups of workers used similar statistical techniques but reach somewhat different conclusions. Lock and Merrington could not find evidence of clustering of leukaemia, though their data do not provide evidence against clustering of one or other subtypes of leukaemia. They point out that the same statistical technique has shown clustering of cases of Burkitt's lymphoma in Africa, and furthermore that other statistical methods, while showing clustering of infectious diseases such as poliomyelitis and infectious hepatitis, have failed to show clustering in leukaemia. However, Till and colleagues give some support, though weak, for the general hypothesis that cases of leukaemia tend to occur in clusters more often than would be expected by chance alone, the evidence for clustering being stronger at birth than at onset of the disease. They thus provide some evidence for the possibility of the existence of a contagious agent in human leukaemia.

The difference between the conclusions reached in the two papers are probably the result of differences in the data analysed. The negative findings of Lock and Merrington,

1 Gross, L., Proc. Soc. exp. Biol. (N.Y.), 1951, 76, 27.
2 Jarrett, W. F. H., Proc. roy. Soc. Med., 1966, 59, 661.

Negroni, G., ibid., 1966, 59, 662.

- Aubertin, C., and Bosviel, P. G., Arch. Mal. Cour, 1923, 16, 696.

s Kellett, C. E., Arch. Dis. Childh., 1937, 12, 239.

- Knox, G., Brit. F. prev. soc. Med., 1964, 18, 17.

" Knox, G., Brit. F. prev. soc. Med., 1964, 18, 17., L., Lancet, 1964, 2, 136.

- Mainwaring, D., Brit. F. prev. soc. Med., 1966, 20, 189

- Ederer, F., Myers, M. H., and Mantel, N., Biometrics, 1964, 20, 626. Barton, D. E., David, F. N., and Merrington, M., Ann. hum. Genet., $1965,29,97$

1 Ager, E. A., Schuman, L. M., Wallace, H. M., Rosenfield, A. B., and Gullen, W. H., f. chron. Dis., 1965, 18, 113 .

12 Lundin, F. E., Fraumeni, J. F., Lloyd, J. W., and Smith, E. M., 7. nat. Cancer Inst., 1966, 37, 123.




while statistically valid, would not necessarily exclude the existence of an infectious agent in human leukaemia. If, on the other hand, leukaemia is a truly infectious disease, it would be more useful to look for an association between the date and place of residence of one child during the period of infectivity and that of another child during the period of susceptibility to the disease. This suggestion might be extended to a study of the parents of affected children, since they will have had the closest and longest contact with the child. But this illustrates the complexity of the epidemiological problem, since nothing is known of these presumed periods of infectivity and susceptibility, and if the proposition is valid the collection of such information will depend on the development of more refined analytical methods.

The hypothesis that human leukaemia is a contagious disease is appealing, and the evidence from the animal leukaemias provides in itself sufficient reason for the experimental approach in studying the human disease. Isolation of a causative organism offers the hope of rational and effective treatment, both immunological and chemotherapeutic, which in the final analysis can be achieved only in the experimental laboratory. But apart from providing evidence for infective agents the epidemiological approach might point to environmental factors which could be controlled. If leukaemia is an infectious disease it must be one of a very special kind, and perhaps the epidemiologist will discover some of these peculiarities. Moreover, in view of its potentially useful epidemiological value the history of all cases of leukaemia should be as detailed as possible and should include information on exposure to other human infections or prolonged contact with animals, insects, and chemical agents.

\section{Diverticular Disease of the Colon}

Maxwell Telling and O. C. Gruner, ${ }^{1}$ of Leeds, gave an exhaustive account in 1917 of the natural history of diverticulosis of the colon. But not until recently was much attention paid to the aetiology of this common and increasingly important condition.

The diverticula may occur anywhere in the colon but congregate especially in the sigmoid. They lie in two columns alongside the lateral taeniae coli, where they are often overlapped by the appendices epiploicae. Unlike diverticula of the small bowel, which project into the mesentery, the colonic diverticula never protrude primarily into the mesocolon. The distribution of colonic diverticula corresponds precisely to the points of penetration of the blood vessels into the bowel wall, as $\mathrm{H}$. Drummond ${ }^{2}$ first showed, and they doubtless produce areas of weakness in the colonic musculature.

Basil Morson ${ }^{3}$ made an important contribution to our knowledge of the aetiology of this disease by taking attention away from the saccules themselves and concentrating more on the colonic wall. He reported his investigations of 173 specimens of colon removed for diverticulitis at St. Mark's Hospital, London. Of these, 112 (64\%) showed evidence of diverticulitis, which was extersive in 67 and focal in 45 cases. In 61 specimens there was no inflammation at all, and 5 of these indeed did not even show diverticula, yet in all cases operation had been performed because diverticulitis had been diagnosed on both clinical and radiological evidence. However, all the specimens showed striking abnormalities in the muscle wall. The taeniae coli were thickened and almost cartilaginous ; the circular muscle was also thickened and arranged in concertina-like folds, with the orifices of the diverticula opening between their corrugations. This thickening of the plain muscle appeared to be a shortening rather than a true hypertrophy, and it accounted for the characteristic redundancy of the mucosa, which was itself thrown into folds and appeared to contribute to the obstruction so common in this condition.

N. S. Painter and S. C. Truelove ${ }^{4}$ have shown by cineradiography and other methods that the resting pattern of pressures in the normal sigmoid colon and in the colon affected by diverticulosis is the same, but very high pressures develop in the diseased segments in response to morphine and prostigmine. In these cases cineradiography showed that the colon was divided by contraction rings into a series of segments whose outflow was obstructed, and the consequent localized high pressures were seen on occasions to distend the related diverticula considerably. There is thus in diverticular disease good evidence of abnormal segmentation and the gereration of high pressures after certain drugs, together with histological proof of an abnormal circular muscle. Investigation of other causes of excessive segmentation-diet, drugs, and purgatives, for example-may lead to important information on the pathogenesis of diverticulosis. Dietary factors may well be of importance. Diverticulosis is a common condition in so-called civilized communities which enjoy a refined diet and is extremely rare in less sophisticated populations living on a bulky vegetable diet. ${ }^{6}$

Not only are we still ignorant about the exact aetiology of diverticulosis, but also there is a surprising lack of accurate information on its frequency in the population as a whole. The incidence has been calculated from barium-enema studies on hospital patients and from post-mortem examinations, both highly selected population groups. However, the investigations have certainly given some useful information. Thus T. P. Dearlove, ${ }^{7}$ in his extensive necropsy study of nearly 7,000 cases at the Royal Adelaide Hospital, found that diverticulosis was almost unknown under the age of 40 years. In the $40 \mathrm{~s}$ the incidence rose to approximately $1 \%$, in the 50 s to $1.7 \%$, in the 60 s to $3.5 \%$, and in patients over the age of 70 years to $7 \%$. Large series of patients examined by barium enema have shown diverticula in 5 to $10 \%$ of the cases.

In this issue of the B.M.f. Dr. Truelove together with Drs. O. N. Manousos and K. Lumsden present an important study of a barium follow-through examination on 109 persons without gastrointestinal symptoms (page 762). Twenty were found to have diverticula. Above the age of 6015 out of 43 people had them (about one in three), and below that age 5 out of 66 . None of the 14 people under the age of 40 had any diverticula. The condition was more common in women than in men. Though the numbers are comparatively small, the study is of particular value in that it deals with a population either healthy or at least completely free of gastrointestinal symptoms. It therefore gives a good indication of the incidence of colonic diverticula in the general population in Britain.

As to the aetiology of colonic diverticula, it is interesting that these workers, in a separate study reported at page 760 , have found the colonic transport time to be considerably shorter in patients with diverticula than in normal persons,

\footnotetext{
Telling, W. H. M., and Gruner, O. C., Brit. F. Surg., 1917, 4, 468. 2 Drummond, H., ibid., 1917, 4, 407.

Morson, B. C., Proc. roy. Soc. Med., 1963, 56, 798.

Painter, N. S., and Truelove, S. C., Brit. med. F., 1963, 2, 33. - Ann. roy. Coll. Surg. Engl., 1964, 34, 98.

- Campbell, G. D., Brit. med. F., 1967, 3, 243.

Thearlove, T. P., Med. f. Aust., 1954, 1, 470.
} 